\title{
FUROR IN FABULA: \\ LA CRUEL ARAGONESA DE CASTILLO SOLÓRZANO (O DE LA DAMA MONSTRUO) ${ }^{1}$
}

\author{
MARÍA ZERARI \\ Université Paris-Sorbonne, CLEA \\ rmz@orange.fr
}

$\mathrm{H}$

ija de una categoría textual exitosa en el Seiscientos, pese a su endeble soporte poético (Laspéras 1987: 171-175; Rodríguez Cuadros 1987: 2223) y a su escaso lustre literario (Zerari 2012), La cruel aragonesa es una de las seis novelas cortas que encierran las Jornadas alegres (1626) de Alonso de Castillo Solórzano (1584-c. 1648) ${ }^{2}$. Dicha colección ocupa el segundo lugar en la larga serie «novelera» ${ }^{3}$ que, desde 1625 hasta 1649, la pluma del productivo escritor vallisoletano brindó a los lectores áureos; además de composiciones burlescas o jocosas de poeta de Academia ${ }^{4}$, a las que se añaden ficciones largas ${ }^{5}$, un volumen hagiográfico ${ }^{6}$, textos de raigambre histórica ${ }^{7} \mathrm{y}$, sobre todo, cuatro relatos picarescos o apicarados que no carecen de gracia, ni de eficacia novelesca ${ }^{8}$. No obstante, como todo lector actual puede comprobar y como señaló tiempo atrás algún que

\footnotetext{
A Rafael Bonilla, divino amigo de Margo Channing.

2 Para la redacción de este artículo hemos utilizado un ejemplar de la edición príncipe de las Jornadas alegres (Castillo Solórzano 1626), así como otro de la única edición moderna existente, la cual carece de aparato crítico: (Castillo Solórzano 1909: 128-186).

3 Tardes entretenidas (1625); Jornadas alegres (1626); Tiempo de regocijo (1627); Noches de placer (1631); Fiestas del jardín (1634); La quinta de Laura (1649); Sala de recreación (1649). Para todo tipo de detalle bibliográfico, véase Bonilla Cerezo (2012: 245-271).

4 Donaires del Parnaso (1624-1625).

5 Lisardo enamorado (1629); Los amantes andaluces (1633).

$6 \quad$ Sagrario de Valencia (1635).

$7 \quad$ Epítome de la vida y hechos del ínclito Rey don Pedro de Aragón (1639); Historia de Marco Antonio y Cleopatra (1639).

$8 \quad$ Las harpías en Madrid (1631); La niña de los embustes, Teresa de Manzanares (1632); Aventuras del bachiller Trapaza (1637); La garduña de Sevilla (1642).
} 
otro especialista ${ }^{9}$, a pesar de la innegable vitalidad narrativa de Castillo y de «su talento para adaptar el estilo al género que se trajera entre manos» (Bonilla Cerezo 2012: 245), nada en su abundante producción de relatos breves logra elevar a este «artesano inteligente» (Rico 1982: 135) al nivel del raro inventor. Sus novelitas, por lo general muy politically y artistically correct —el conformismo ideológico y la llaneza del estilo bien podrían definirlas - , son un producto de aquel «sistema de pluma fácil y gozosa invención» (Arellano 1989: 13), no exento de cierto profesionalismo con aspiraciones comerciales, que el Siglo de Oro supo acrecentar. De ahí La cruel aragonesa que, ante todo por vicios de lenguaje y composición (repeticiones léxicas, giros trillados, descuidos estilísticos, larguras narrativas, esquematismo analítico etc.), no le llega a la suela del zapato a ninguna de las Ejemplares. Dicho de otro modo, ni La cruel aragonesa, ni las Jornadas alegres —ni la pieza, ni el conjunto- logran abrir algún nuevo camino de tipo estético, por recordar la manoseada expresión cervantina acerca de las Novelas ejemplares ${ }^{10}$.

Por tanto, como hicieron algunos frente a otras obras del vallisoletano (Campana 1992: 7), ante tal texto conviene plantearse la cuestión de la licitud de su lectura hoy en día, puesto que, si bien sabemos tras las observaciones de Calvino ${ }^{11}$ por qué leemos los clásicos, más difícil de entender resulta la motivación de un lector actual, e incluso de un estudioso, frente a un texto menor como La cruel aragonesa, el cual, aunque cuenta algo (sin grandes muestras de elocuencia), tiene poco que decir o, digamos, mucho menos que todo texto importante cuyo discurso y / o manera lo hacen casi inagotable ${ }^{12}$. Más allá de la curiosidad literaria que pueden despertar unas novelerías que ya empiezan a ser conocidas; más allá del interés de tipo histórico que puede nutrir el supuesto costumbrismo de la llamada prosa cortesana y, al fin, más allá de ese dandismo literario, tan magistralmente retratado por el francés Huysmans ${ }^{13}$, que gusta de los raros prefiriendo las luces enfermizas de los minores a los fulgores de los maiores, otra razón puede justificar dicha lectura. Ésta tiene mucho que ver con lo que la crítica ha llamado «el efecto personaje», esto es, «el conjunto de relaciones que unen al lector con los actores de un relato» (Jouve 1992: 108) ${ }^{14}$, pues hasta los protagonistas leve-

\footnotetext{
9 Véase, especialmente, Dunn 1952.

10 Recordemos la sonora afirmación: «Yo he abierto en mis Novelas un camino / por do la lengua castellana puede / mostrar con propiedad un desatino» (Cervantes 2005: 1299, IV, vv. 25-27).

11 Véase Calvino (1994: 13-20).

12 «Un clásico es un libro que nunca termina de decir lo que tiene que decir» (Calvino 1992: 13).

13 Remitimos al tercer capítulo de À rebours (1884) en el que el «autor de culto» Joris-Karl Huysmans describe, en términos finiseculares, la afición del esteta Des Esseintes por los escritores de «la decadencia», cuya veneración tiene su reverso en un arrogante desprecio por los Virgilios, los Horacios y los Ovidios. El texto se puede leer en diferentes traducciones españolas (Contra Natura, 1980; A contrapelo, 1984; Al revés, 1986).

14 Traducimos el texto francés.
} 
mente caracterizados de la novela corta del XviI pueden llegar a ser, para el lector moderno, como probablemente lo fueron para el lector antiguo, algo más que el simple «rosario de palabras» del que hablaba Robert Luis Stevenson. Y es así que algunos personajes vienen a ser objetos de reflexión (relación hermenéutica), cuando no de fascinación (relación personalizada) — con el erotismo más o menos difuso que el vocablo supone ${ }^{15}$ _ , por poseer al mismo tiempo el peso semántico de un avatar textual y la peculiar seducción de un «personaje singular» (Frenk 1977). En cierto modo, tal cosa nos parece que sucede con la doña Clara de $L a$ cruel aragonesa, cuya truculenta trayectoria amorosa no deja de impresionar y de plantear interrogantes acerca de la feminidad y de su representación, o del eros y de su afloramiento en la novela barroca. De modo que, con estos escuetos apuntes, nuestro sencillo y atrevido propósito no es otro que el de interrogarnos sobre el atractivo de La cruel aragonesa, examinando ante todo los principales rasgos de su heroína, no sin apuntar previamente algunos de los aspectos del texto.

\section{Observaciones generales}

A imagen de La mayor confusión de Juan Pérez de Montalbán —conocida novela sobre un doble incesto, pronto atacada antes de ser censurada ${ }^{16}$ - La cruel $^{-}$ aragonesa pertenece a ese grupo de novelas cortas que parecen haber integrado, en parte, la literaria lección de la edificante «historia trágica», tal como, tras Boccaccio, la formularon Bandello, los demás novellieri y bastantes autores franceses del XVI y XVII (los adaptadores Boaistuau y Bellforest, Rosset, Camus, etc.), atentos lectores de Aristóteles y del Seneca tragicus redescubiertos por el humanismo renacentistas. Así, a imitación de las llamadas historias trágicas (es decir, específicamente, de «lamentable» tema), leídas por los lectores áureos en italiano o en sus edulcoradas traducciones al castellano (Aldomà García 1986; Arredondo 1989), estas novelitas hispánicas no vacilan en evocar todo tipo de crímenes, con insistente intención moralizadora. En cualquier caso, por su discurso ostentosamente moral $^{17}$, no sin algo de moralina, y su pintura de un «eros rebelde» (Jeanne-

15 Escribe Pascal Quignard, con algo de poesía: «Quiero meditar acerca de una difícil palabra romana: la fascinatio. El fascinus es en latín lo que en griego se dice phallos. Los cantos que lo rodean se llaman «fesceninos». El fascinus detiene la mirada hasta el punto de que ésta no puede apartarse de él. Los cantos que inspira están en el origen de la invención romana de la novela: la satura» (Quignard 2005: 8).

16 Véase Pérez de Montalbán (2014: 685-70) y, al respecto, Dixon (1958) y Rodríguez Cuadros (1987: 51-56; 127-165).

17 A fin de justificar la escabrosa historia que va a ser relatada, el narrador del suceso declara: «Comienzo mi discurso, cuya moralidad amonesta a que nos rescatemos de nuestros criados para que no sepan las cosas que importasen a nuestro honor [...]. Repréndese cuán feo parece en las mujeres persuadir a los hombres que las quieran estando descuidados de poner su afición en ellas. Afea la dañosa costumbre de hablar mal en ofensa del prójimo [...]. Da escarmiento a los que 
ret 2003) — esto es transgresivo, indomable, violento y desafortunado-, por sus truculentos motivos, y por su sanguinaria protagonista, La cruel aragonesa forma parte de la vertiente grave del corpus cortesano, junto a los «desengaños» (1647) de María de Zayas o a los «sucesos trágicos» (1685) de Luis de Guevara, entre otras novelas de tinte oscuro (Zerari 2012). Sin embargo, por estar encerrada en una colección ligera y variopinta, que obedece al precepto de la varietas y a su consecutivo efecto de reverberación, esta novela no alcanza del todo la gravedad trágica que los novellieri, y más aún los novelistas franceses, quisieron conferir a sus libros a fin de ennoblecer una categoría de mala reputación (pensemos en la condena inquisitorial del Decamerón) y sin gran prestigio textual. Además, el mismísimo marco narrativo de las Jornadas alegres descarta lo grave, al poner en escena, de manera poco sustancial, a un amable conjunto de dones y de doñas con escasas señas de identidad, quienes deciden referir «un suceso con su moralidad» (Castillo 1909: 17) en el contexto sosegado de un viaje (en coche y con escalas) libre de conflictos o antagonismos. Queda claro, por lo tanto, que el marco de las Jornadas se halla muy por debajo de la magistral y ponderosa cornice del Decamerón con su representación espantosa de la peste negra.

Con todo, la trama de La cruel aragonesa — de esta novelita que, como sus compañeras, oculta la etiqueta «novela» por haber florecido en los primeros años de la prohibición editorial de las novelas y comedias en los reinos de Castilla (Moll 1974) — es la de una historia de amor que se torna en historia de odio y venganza. Su intriga vengativa recuerda, según algunos críticos, una de las Cento novelle de Sansovino (IX, 6) pero, a decir verdad, lo hace de manera bastante imprecisa, en entendida opinión de Dunn (Giorgi 2012: 81). Como bien lo anuncia un título a la vez transparente y atrayente, que parece copiar el de una tragedia de Virués escrita a finales del xvi (La cruel Casandra), el «suceso» pone de relieve la figura de una mujer cruel, es decir, sanguinaria y desalmada, llamada doña Clara, por evidente antífrasis. Esta dama de Zaragoza - «madre de tantos santos, que en rigurosos y crueles martirios ofrecieron sus vidas a su Criador» (Castillo 1909: 130)_, de esquiva condición, llevada por la curiosidad y la vana voluntad de rivalizar, se enamora súbitamente de don García, el pretendiente de su amiga doña Marcela. Su desvergonzado deseo será frenado, no por el liviano don García, sino por don Artal, despreciado pretendiente, quien, con la ayuda de la criada Teodora, logrará alejar al nuevo galán, haciéndose pasar por el festejador de doña Clara. Por consiguiente, el casamiento de don García con doña Marcela engendra la desesperación y la ira de la aragonesa. Es entonces cuando la dama, volviéndose malévola y vengativa, recurre a una hechicera para provocar la muerte de don

consultan hechiceras y adivinos, mayormente para quitar las vidas a otros, y asimismo sírvenos de ejemplo para que huyamos de la obstinación, en nuestras venganzas [...]» (Castillo Solórzano 1909: 129-130). 
Artal, de Teodora y, a la postre, de doña Marcela. Escandalosamente, su enojo irá creciendo y culminará en una iglesia, ante los restos mortales de Artal y Teodora. Tras su reconciliación con don García y su casamiento con el cincuentón don Rodrigo, la violenta y adúltera aragonesa termina su indecente y asesina trayectoria mortalmente apuñalada por su esposo, siendo su muerte ejemplar el «digno castigo de sus rigurosas crueldades» (Castillo 1909: 182).

Como se puede apreciar, el «suceso» narrado por un tal don Carlos no peca de jocoso. No obstante, para que lo serio maride con lo donoso, antes de que esta tercera novela ceda el paso a la siguiente, aflora en el texto un divertido romance. Don Carlos se encarga de leer «un romance hecho a una sangría de una dama, que después de haberse dejado hacer el sacrificio, se fue a la comedia, donde se desligó la venda y fue la sangre, causándole desmayo» (Castillo Solórzano 1909: 184-185). Reconocemos en el aludido romance la chispa poética del autor de los Donaires del Parnaso en los que, a menudo, «pone en solfa los hábitos del siglo» (Bonilla Cerezo 2008: 52). Sea lo que sea, y a modo de conclusión de la sangrienta novela, el motivo mundano de la sangría sustituye al tremendo tema del crimen de sangre. Salerosa manera de recordar al lector que se encuentra en el espacio del divertimiento variado y variable. A pesar de ser un texto (a)sombroso, La cruel aragonesa termina con la amena claridad que la donosura final le confiere. Así, la lectura puede proseguir apaciblemente, sin grandes perturbaciones, ni grandes purgaciones. Pero dicha novela puede haber rayado con cierta delectatio: no tanto con aquella delectación trágica glosada por Lucrecio, en el canto segundo de su De rerum natura — que determina la tranquilidad propia por comparación con el dolor ajeno- , como con un tipo de «placer del texto» peculiar: el placer que nace del «efecto personaje» (Jouve 1992); un efecto que puede coincidir con la impresión de haber hecho «un encuentro» verdadero (Jouve 1992: 261) — si se consideran a los personajes-personas de la literatura psicológica-, o bien, por lo que concierne a las figuras áureas, de haber hallado una imagen, una pura superficie, pero con algo de la seducción de un icono (del mal, en este caso). Y, si antiguamente tal perspectiva era rechazada socialmente por cuestión de moral, no sería de extrañar que, además de horrorizados, los lectores del Siglo de Oro quedaran un tanto turbados ante las sugestivas imágenes generadas por la evocación de una feminidad tan intensa como transgresora.

\section{LUGARES CORTESANOS: DESAMOR / (CURIOSIDAD ) / AMOR / (DOLOR)}

Antes de que prorrumpa en el texto lo horrendo y lo funesto mediante una escena espectacular, si nos centramos en el argumento de La cruel aragonesa, constatamos que, de manera casi anodina, todo parte de la curiosidad de la citada doña Clara. En pocos párrafos, la tópica frialdad de la «severa y altiva» dama 
(Castillo Solórzano 1909: 131), presentada como atributo principal en la concisa y muy convencional descripción del personaje ${ }^{18}$, deja paso al eficiente topos de la curiositas:

En el ínterin que la dama aguardaba ocasión para hablar a su amiga, se ofreció tratar con [la criada] Estefanía de varias cosas, preguntándola con curiosidad muchas menudencias de doña Marcela, hasta querer saber quién la servía y a quién mostraba inclinación (Castillo Solórzano 1909: 132).

Así, a pocas páginas del arranque de un relato de carácter «cortesano», asoma el tema de la curiosidad (entendida como deseo de conocer cierta verdad oculta o de ver algo recóndito y prohibido, cuando no sagrado), tan presente en las tradiciones antiguas - mediante las figuras de Psique, Pandora, Penteo, Ulises o Acteón, por una parte, y de Eva, por otra (Jacques-Chaquin y Houdard 1998) - y tan soberbiamente revisitado por Cervantes en la Novela del curioso impertinente. Como bien se sabe, en el texto cervantino la curiosidad de Anselmo, francamente obsesiva, es, para el joven marido, un turbio y penoso deseo de conocer del todo a su mujer, poniendo a prueba la fidelidad de la esposa. De hecho, expresándonos en los términos agustinianos de La Ciudad de Dios, el desatino de Anselmo parece proceder aún más de la libido sciendi (relativa al saber) que de la libido sentiendi (referente a todos los apetitos del cuerpo), ya que Anselmo, mediante la ayuda de Lotario, bien parece desear abrir a Camila para penetrar la «verdad» de su mujer ${ }^{19}$, por recurrir al verbo que emplea Georges Didi-Huberman en su evocación de la «Venus de los médicos» (1781-1782): hermosa y espantosa escultura anatómica de cera teñida, con todos los órganos internos de una mujer verdadera, fabricada por Clemente Susini (1754-1814) para poder ser abierta y desmontada por los estudiantes de medicina, que se encuentra en el Museo Zoológico de La Specola de Florencia (Didi-Huberman 1998: 382-390). En realidad, en la novelita de Castillo Solórzano, la curiosidad de doña Clara resulta mucho menos metafísica que la del enigmático personaje cervantino, pero no por ello se mostrará menos infausta y mortífera. Se trata de una curiosidad hueca y mundana, claramente vinculada a la libido dominandi (originada en el orgullo), si bien pronto sentimental ${ }^{20}$, y alimentada por los dichos de la criada Estefanía (acerca de los

18 «A ninguno de cuantos le servían mostraba doña Clara inclinación por ser de condición severa y altiva, con lo cual los traía desvelados y con poco sosiego, buscando ocasiones en qué agradarla» (Castillo Solórzano 1909:131).

19 «[...] Te hago saber, amigo Lotario, que el deseo que me fatiga es pensar si Camila, mi esposa, es tan buena y tan perfecta como yo pienso, y ni puedo enterarme en esta verdad si no probándola» (Cervantes 2004: 331).

20 «Estos versos [que había escrito don García a un gracioso lunar que la hermosa doña Marcela tenía en la mejilla derecha], la envidia que a la amiga la tenía, y el buen talle, y partes del galán, 
amores de doña Marcela con don García) a petición de la propia doña Clara. De hecho, al inicio, dicha dama propiamente desamorada, esto es, «esquiva, desdeñosa, sin amor» (Diccionario de Autoridades: II, 100), por estimarse en demasía - como les pasa a otras damas de la novela, muy preciadas de sí mismas ${ }^{21}$ quiere saber de los amores de su amiga doña Marcela. En otras palabras, la figura del orgullo y de la frialdad arde en deseos de saber, al sentir un tipo de curiosidad que se relaciona con la intimidad ajena y el lado oscuro del yo, y bien se sabe que cierta curiositas, concebida como un «vicio», fue severamente condenada por los antiguos, entre otros, por el san Agustín de Las Confesiones (X, 35) y, de manera menos categórica, por el Tomás de Aquino de la Suma teológica (quest. 167). En cualquier caso, la relación entre la autoestima excesiva, la indiferencia erótica y la curiosidad amorosa, de esencia voyeurística y hasta sádica, se encuentra en otros textos de la literatura áurea, empezando por los del afamado Fénix, quien, recordémoslo de paso, habría de elogiar a Castillo en su Laurel de Apolo (1630), además de haber trabado amistad con los compañeros de novelística Juan de Piña y Juan Pérez de Montalbán (Ripoll 1991: 90 y 123). Así pues, por mencionar tan solo un ejemplo ideal, en el primer acto de El perro del hortelano (c.1613), antes de rendirse al amor, la severa condesa Diana, picada por la curiosidad, procede a alguna que otra «brava inquisición» (Vega 1990: 84) concerniente a impropios y subalternos amoríos. En La cruel aragonesa, esta vana curiosidad femenina tiene varios efectos: primero, como hemos indicado, despierta la envidia de la desdeñosa dama por la amada y celebrada amiga; después, provoca el enamoramiento de la «curiosa doña Clara» (Castillo Solórzano 1909: 133), quien, ilustrando el tópico de la inclinación por imitación, ama a don García por verle amar a otra; por fin, tras haber motivado el recurso del crimen pasivo (mortal hechicería contra don Artal y Teodora), el dolor será otra de las consecuencias de la curiosidad amorosa.

Vemos que, desde una perspectiva algo trillada y apolillada, el texto evoca el amor como fruto de la envidia — que también es hostilidad, malevolencia u odio, en su forma latina invidia - y el orgullo, puesto que doña Clara se enamora, si se quiere, por sentido de la rivalidad y del amor propio. Igualmente, después de un juego de seducción, amablemente cortesano, entre Clara y don García (convencional proceso de cartas y declaraciones que la novela corta repetirá hasta finales del XVII casi ad nauseam), el placentero e impertinente amor de doña Clara por el galán ajeno coincide repentinamente con ese inexorable amor profano, en su versión pasional, que «crece con los obstáculos» (Vaenius 1608: LXXXVI), según

dispusieron la voluntad de doña Clara, de suerte que se determinó a hacer todo lo posible por tiranizársele para sí» (Castillo Solórzano 1909: 134-135).

21 Véase, por ejemplo, La soberbia castigada (Camerino 1624). Sobre las novelas de José Camerino, véanse Bonilla Cerezo (2010: 46-63) y Zerari (1995). 
reza en el mote de uno de aquellos emblemas de tema amoroso que se pusieron de moda en Europa entre el último cuarto del siglo XVI y el primero del siglo XVII ${ }^{22}$ y cuyos ecos, ampliamente ovidianos, se perciben en el ideario amatorio pagano-cristiano que propaga la prosa cortesana. Pues bien, en La cruel aragonesa, estos obstáculos se encarnan en doña Marcela (la otra), don Artal (el «poco secreto» y «celoso» pretendiente de doña Clara) y Teodora (la criada de doña Clara y codiciosa cómplice de don Artal). Convertida en fuerza todopoderosa, el amor de doña Clara se hará vengativo y criminal, tras el rechazo de don García y su casamiento con doña Marcela a cuenta de la traza de Artal y Teodora. No obstante, antes de transformarse en pasión y furia aniquiladora, este amor - cuya azarosa génesis y aventurado desarrollo son los temas predilectos de la novela poscervantina, como buen producto estandarizado de otros géneros literarios (Rodríguez Cuadros 1987: 26) - se envuelve en dolor.

La «pena» de nuestra dama es una pálida variante del dolor trágico, mas, como éste, nace de la iniuria, o al menos de lo que doña Clara experimenta como tal. En efecto, el rechazo de don García ${ }^{23}$ y su casamiento se convierten, para la burlada Clara, en una punzante herida desbordante de aflicción y de ira, sentimientos que conlleva el dolor trágico ${ }^{24}$, como bien se ve, por ejemplo, en los personajes senequianos de Medea y Hércules. No sin lógica, el relato evoca gestos arcaicos, históricamente atestados, de desolación (cabellos arrancados, rostro y cuerpo arañados... $)^{25}$, que la tragedia antigua y, posteriormente, las historias trágicas tanto italianas como francesas, incluyeron en sus escenas de desesperación, principalmente amorosa. Y es así que, por una parte, la noticia de las bodas de don García y doña Marcela y, por otra, la visión de la felicidad conyugal de la pareja, ocasionan, en doña Clara, un profundo dolor, así como una ira lacerante, la cual encuentra en el propio cuerpo de la defraudada dama un lugar de expresión:

Acabose la opulenta merienda con el día, y despidiéndose doña Clara de doña Marcela y de su esposo, se fue a su casa, a donde, retirada, pagaron sus cabellos y su rostro el enojo que traía con el ya casado galán (Castillo Solórzano 1909: 171).

\footnotetext{
22 Sobre este «subgénero» emblemático, cuyos máximos representantes fueron los neerlandeses Heinsius, Vaenius y Hooft, véase Sebastián (2001).

23 «Quince días estuvo [doña Clara] en la cama indispuesta, con la pena que recibió de leer el papel [de don García]» (Castillo Solórzano 1909: 161).

24 «Para los romanos se trata de un proceso normal: un hombre, una mujer, que ha padecido una iniuria siente necesariamente un dolor, una pena, aegritudo. Esta pena lo ensombrece, lo aparta de los demás, le quita las ganas de vivir. Suscita también su enojo, ira; este sufrimiento no se puede disociar de lo que llamamos el resentimiento. Y es este enojo que, según la opinión común, el que le otorga al dolido la violencia, la fuerza — vis — necesaria para su venganza» (Dupont 1995: 64). Traducción propia.

25 Véase Bourgeaud (2008).
} 
En cierto modo, dicho episodio de auto-violencia responde a una escena anterior, de mayor envergadura y claramente central, en la que doña Clara manifiesta descomedidamente su crueldad contra otros cuerpos. Pues el amor contrariado (antes de poder ser consumado en el pecado) engendra un primitivo furor que transforma la «discreta y hermosa dama» (Castillo Solórzano 1909: 130) de los inicios cortesanos en una furiosa absoluta.

\section{EL SUCESO «TRÁGICO»: RETRATO DE FEMINA FURENS EN DAMA BARROCA}

El amor fallido, el dolor que supone la insatisfacción de un indomable deseo por don García y la rencorosa ira que suscita, en doña Clara, el recuerdo de la traza de don Artal y Teodora, provocan una reacción desmedida e irracional que bien parece arrastrar la novelita de Castillo hacia el espacio ficcional de la historia trágica, de raigambre ítalo-francesa, donde no solo reinan la falta y el castigo, la ley y su transgresión, sino también la caótica desmesura, la afición a la venganza, el abominable crimen y la consecutiva aniquilación de un orden. Con el tema de la «venganza» (voz recurrente en el texto, así como en las historias trágicas y las tragedias de los siglos XVI y XVII), poco a poco, el relato de suaves tonalidades cobra colores muy oscuros. Tamaño cambio de tono, por no decir de registro, se hace, como se va entendiendo, mediante la principal protagonista de la novela, esta ingrata aragonesa, pronto inhumana, por efecto de sus desdenes iniciales, de su empeño amoroso y de su sucesiva violencia. En verdad, doña Clara adquiere el estatuto de perfecta cruel, de encarnación del mal, no tanto por recurrir primero a los poderes maléficos de una hechicera, a fin de eliminar a tres personas adversas a su deseo erótico - lo que ya implica, claro está, la muy pecaminosa y condenable complicidad brujeril—, como por comportarse, a continuación, con la fiereza de una cruenta asesina sin piedad ni escrúpulos. En consecuencia, tras el alejamiento y las bodas de su amado, y después de la muerte de su padre, doña Clara ve mermadas, propiamente, las humanas cualidades. Y este fenómeno es referido de manera explícita en el texto:

[...] el día que vio muerto a don Artal, y Teodora, como estaba en ella tan vivo el deseo de la venganza, se consoló de la pérdida de su padre; infundiéndosele en su femenil sujeto un afecto tan cruel que la hizo degenerar de su primero ser, manifestándolo en la misma noche que enterraron a los dos difuntos, con una acción la más inhumana que en historias antiguas y modernas se ha visto escrita (Castillo Solórzano 1909: 163).

Este pasaje, de índole superlativa, que tiende a despertar la curiosidad del lector anunciando una acción extremada acorde con los requisitos de la admiratio, opera la transición definitiva de un yo a otro o, mejor dicho, preludia una 
metamorfosis. Así que, tal como ocurre en las tragedias de Séneca, en las traducciones y reescrituras trágicas del Cinquecento (las de Dolce o las de Cinzio, por ejemplo), o en el «Bandello» italo-franco-español, el furor, esta descomunal locura, repleta de una tremenda violencia, elaborada por el teatro antiguo como categoría trágica (Dupont 1995: 71), se apodera del personaje en el seno de una prodigiosa escena de alteración. Para que el crimen de doña Clara sea absolutamente extraordinario e ignominioso y corresponda a lo que la lengua latina llamaba el $n e f a s^{26}$, la alteración o transformación se produce de noche — que, según el refrán, es «capa de pecadores» y circunstancia agravante, según antiguas legislaciones (Pech 2000: 271) — , en una iglesia, el lugar sagrado por antonomasia. Aparece así en el texto una escena nocturna, de aspecto sabático, envuelta en un acusado tenebrismo. El macabro tableau que ostenta el pasaje muestra la figura de una dama sumida en una semi-oscuridad frente a las «cajas» en las que se hallan sepultados, por su culpa, don Artal y Teodora. Como en los grandes monólogos de la tragedia antigua (del Seneca tragicus, en especial) y moderna (tragedias filipinas), la dama de este tiempo se expresa con inmoderada cólera y despiadadamente al arrancarle el corazón a su antiguo enemigo, quien erró por parlero y mentiroso:

-Este es el cuerpo del más falso y aleve caballero de los nacidos, cuya alma por no haber sido lo que debía ser [...], creo yo que padece en las infernales moradas las penas que merecieron graves culpas, causadas por su desenfrenada lengua, que siempre fue polilla de las honras ajenas.

Esto decía al mismo tiempo que con un cuchillo que llevaba hacía pedazos el hábito del seráfico san Francisco, con que don Artal se había enterrado, y luego la mortaja; [...] y sin darla horror y asco de lo que hacía, metió [doña Clara] la mano por la herida que había hecho, sacándole el helado corazón [a don Artal], al cual viéndole en sus manos dijo:

-Este fue el archivo que guardó tantos ofensivos pensamientos, que forjó tantas ignominias contra sus prójimos, y la aljaba de donde salían tantas ofensas para todos. Entre las cuales salió desta aleve oficina, el rayo que desacreditó mi honor, para que don García no fuere mi esposo. Decía esto con tanta cólera y pasión que parecía despedir centellas por los ojos; y de cuando en cuando, rabiosa, como está la leona despojada de sus recién nacidos hijos, daba bocados en el difunto corazón (Castillo Solórzano 1909: 165-166).

Las citadas líneas evidencian una degeneración: tópicamente, la dama es animalizada y comparada con una leona ${ }^{27}$, pero su comportamiento corresponde más bien al de una antropófaga. A imagen de la historia trágica del XVI $-\mathrm{y}$

\footnotetext{
26 «El nefas es un crimen extraordinario y se distingue del crimen ordinario, scelus, por ser inexpiable» (Dupont 1995: 57). Traducción propia.

27 «Fiereza tenía el alma de Leonor, o de tigre» (Piña 1627: f. 57v).
} 
especialmente de la francesa que tanto manejó la imagen del cuerpo mutilado-, con la repelente evocación del corazón devorado del difunto don Artal, nuestro texto se asemeja a los «textos-espectáculo» de Boaistuau, Rosset o Camus (Cremona 2010: 189-201). Vemos así que el motivo medieval del corazón comido, reutilizado en el Decamerón (IV, 9), encuentra aquí una versión, en cierto modo feminizada y como erotizada (aunque sea de manera indirecta), en la que la mujer, lejos de ser la víctima de un boccacciano marido tan celoso como sádico, o de un zayesco verdugo, muerde con sugestivo anhelo, y oscuro placer, el emblemático órgano por afán de venganza personal y voluntad propia, y no a pesar suyo. En definitiva, la vindicativa doña Clara llega a parecerse a una dama monstruo, semejante a las mujeres sangrientas de ciertas Novelle (1553-1574) de Matteo Bandello, como sugiere sencillamente, en traducción, la «Historia nona» de las Historias trágicas exemplares, sacadas del Bandello Veronés (1589 y 1603) ${ }^{28}$. Podríamos decir, incluso, que la cruel aragonesa se convierte en una suerte de arpía, no en el sentido de hermosa, deshonesta y ávida cortesana, pronto ilustrada por Castillo en Las harpías en Madrid y coche de las estafas (1631), sino en su acepción mitológica de monstruo femenino harto vengativo y devorador. De hecho, su monstruosidad moral, si no mental, cuadra perfectamente con ese interés del Barroco por lo extraordinario, los monstruos de la naturaleza, viva herencia de la atención del primer Renacimiento al respecto (Blanco 1994).

Monstruo mujer, responsable de tres muertes causadas a distancia por una hechicera, la malvada doña Clara no sería del todo la «cruel aragonesa» sin algo de cruor, o de «sangre», sin ser la activa causante de algún derramamiento sanguíneo. Por consiguiente, al final de dicha escena nocturna, que bien pudiéramos calificar (anacrónicamente) de escena gore, la monstruosa dama acuchilla a un testigo: al escandalizado sacristán. Por ser la escena ya tan indecorosa, el relato no describe la sangre derramada, pero la expresión «le había dado una puñalada por la garganta» (Castillo Solórzano 1909: 167) es ya lo suficientemente sugerente para evocar con eficacia la imagen de una herida abierta y desbordante de hemoglobina.

A consecuencia de todo esto, la dama degenerará para siempre. La continuación del relato aludirá a los repetidos y «dolorosos suspiros» (Castillo Solórzano 1909: 168) oídos por doña Clara sin que su «varonil ánimo» piense en el sagrado «sacramento» de la confesión, viviendo «como gentil» (Castillo Solórzano 1909: 168); también evocará el relato sus lascivos y adúlteros amores con don García, tras la muerte de doña Marcela (víctima de la hechicera contratada por doña Clara)

28 Utilizamos la segunda edición del libro, que fue publicado por primera vez en 1589, en Salamanca, por Juan Godínez de Millis. En la «Tabla» del volumen se lee: «Historia Nona. De la crueldad de Pandora dama Milanesa contra el propio fruto de su vientre, por verse desamparada de quien le avía engendrado. Repartida en quatro capítulos» (Historias trágicas... 1603).

Edad de Oro, XXXIII (2014), pp. 241-256, ISSN: 0212-0429 
y después de que, por interés, doña Clara se haya casado con el severo don Rodrigo. Prueba del ansia pasional de la dama, la aragonesa acudirá de nuevo a la magia negra de la hechicera a fin de ganarse la fidelidad de su amante: el tan deseado don García. Por fin, las últimas páginas del texto pintarán las sospechas del celoso marido a la vez que la solución radicalmente vengativa adoptada por él para lavar su honor, siendo doña Clara (o cuerpo del delito), al escaparse su amante, el único personaje que pagará sus maldades y fechorías con una deplorable muerte sin confesión.

Con todo, como bien se puede deducir de todo lo dicho, y pese a estas peripecias finales - las cuales, para el antiguo lector, acaso podían convertir el libro de Castillo en una especie de entretenido page turner-, lo que domina en el texto y le otorga su poder de paradójica seducción es, de manera manifiesta, la figura de doña Clara. Esta hermana menor, liviana y caprichosa, de las furiosas trágicas, senequianas y renacentistas, ideada, en teoría, para moralizar a los lectores merced al recurso del horror y el castigo del crimen, viene a confirmar el poder de captación de los personajes negativos y quizá, más aún, de las protagonistas relacionadas con el mal, cuyo venenoso encanto es el de la peligrosa tentación, o, en otras palabras, el de la mujer fatal, a la vez muy temida y un tanto deseada. En el caso de doña Clara, su peso textual es de naturaleza intertextual, por ser una figura no muy hondamente caracterizada, mas repleta del tenebroso carisma de toda una tradición artístico-literaria muy atenta a la feminidad, a la par que muy misógina (Mattews Grieco 1991). Ahora bien, si su trayectoria absolutamente criminal la pone bajo el conocido signo de «Medea, Progne y Sicilia», como precisa el narrador don Carlos ${ }^{29}$, su singularidad, por plagiar a Frenk, se fundamenta en una autonomía de hiperbólica expresión para una aragonesa de un muy vago y ficticio Seiscientos: ella es quien curiosea, interroga, desea, elige, decide, manda matar, se casa y vuelve a seducir a don García. El personaje parece regido por su propia ley, si bien ésta resulta ser la imperiosa ley del deseo, a menudo padecida y asumida, contrariada y contradictoria, condenable y condenada, según los criterios de la moral cristiana. Y es en esta hipertrofia de un yo rebelde y contradictorio donde bien parece reflejarse la peculiaridad de doña Clara, figura, sin duda, marcadamente barroca, por su absoluta desmesura, sus tensiones internas y sus desacertadas contradicciones (Dubois 1973: 129-140).

Por lo que respecta a las audacias de la sombría heroína y a este erotismo «larvado» que desprenden las novelas cortesanas (Goytisolo 1977; Rey Hazas 1990), se nos antojan muy sugestivos en La cruel aragonesa. Dicho erotismo, que pocas

29 «Dio fin don Carlos a su ejemplar discurso, y mucho gusto al auditorio de habérsele oído, si bien a algunas de aquellas damas dejó quejosas de que, siendo fábrica de ingenio, hubiese hecho aquella dama tan cruel cosa ajena de su sexo [...], de lo cual se disculpó, diciéndoles no ser muy ajena la crueldad de las mujeres agraviadas, dando este ejemplo las historias con Medea, Progne y Sicilia, que mostraron su crueldad contra su misma sangre» (Castillo Solórzano 1909: 183). 
frases y pocas voces del texto explicitan al evocar la relación adúltera con don García (encontramos tan sólo las menciones «lecho» y «fuéronse a acostar los dos») - a diferencia de lo que suele ocurrir en las novelle - , cobra su mayor expresión en la violencia de la Cruel. En efecto, bien se entiende que la energía y el goce criminal de la heroína son el mero reflejo de un temperamento intensamente ardiente, un tiempo ocultado por el anverso de una excesiva frialdad. A fin de cuentas, en la novela de Castillo Solórzano, el dark continent, protagonizado por doña Clara, se consume en un crimen horrendo a expensas de un eros des-moralizado que ningún casamiento dichoso, ningún happy ending tiende a moralizar.

La cruel aragonesa constituye, pues, una atrayente novela de oscura tonalidad. A pesar de su propósito moralizador, forzosamente programado y marcadamente reivindicado, el texto de Castillo Solórzano se presenta como una entretenida y atrevida historia de eros y thanathos llena de una espectacular violencia y de un erotismo subtextual. De hecho, si la novelita logra destacarse e incluso lucirse, es por medio de la fábrica de un monstruo mujer: una cruel del siglo XVII. Ente extremado, de hiperbólica expresión, trastornado por el poder del orgullo y la fuerza bárbara del deseo - este infamante revés de la insigne fuerza de la sangre-, la cruel doña Clara se presenta como una impresionante figura intermedia entre la furiosa trágica y la diabólica romántica y posromántica.

Recibido: 30/08/2014

Aceptado: 30/10/2014

\section{OBRAS CITADAS}

Aldomà García, Mireia (1996), «Los Hecatommithi de Giraldi Cinzio en España». En I. Arellano, M. C. Pinillos, F. Serralta y M. Vitse (coord.), Studia Aurea. Actas del III Congreso de la AISO. Toulouse/Pamplona: Griso - Lemso, III, pp. 15-21.

Arredondo, María Soledad (1989). «Notas sobre la traducción en el Siglo de Oro: Bandello francoespañol». En Francisco Lafarga (coord.). Imágenes de Francia en las letras hispánicas. Barcelona: PPU, pp. 217-226.

Arellano, Ignacio (1989). «Alonso de Castillo Solórzano: noticia biográfica». En Alonso de Castillo Solórzano, El mayorazgo figura. Ignacio Arellano (ed.). Barcelona: PPU, pp. 13-19.

Blanco, Mercedes (1994). «Le baroque et le monstrueux. À propos de Góngora et de Gracián». En Des monstres. Fontenay-aux-Roses: Cahiers de Fontenay, pp. 131-152.

Bonilla Cerezo, Rafael (2008). «Pesadilla de médicos, veneno de enfermos: la sátira científica en Alonso de Castillo Solórzano». Edad de Oro, 27, pp. 47-104. (ed.) (2010). Novelas cortas del siglo XVII. Madrid: Cátedra. (2012). «Alonso de Castillo Solórzano: bio-bibliográfica completa» [en línea]. Tintas. Quaderni di Litterature iberiche e iberoamericane, 2, pp. 243-282. Consultado el 2212-2013, http://riviste.unimi.it/index.php/tintas 
Borgeaud, Philippe (2008) (coord.). La mort et l'émotion. Attitudes antiques, Revue de l’histoire des religions, [en línea]. Consultado el 22-08-2014, http://rhr.revue.org/6143 Calvino, Italo (1994). «Por qué leer los clásicos». En Por qué leer los clásicos. Aurora Bernárdez (trad.). Barcelona: Tusquets, pp. 13-20.

CAmerino José (1624), Novelas amorosas. Madrid: Tomas Iunti.

CAmpana, Patrizia (1992). «Introducción». En Alonso de Castillo Solórzano, Tardes entretenidas. Barcelona: Montesinos, «Biblioteca de Clásicos y Raros», pp. VII-XLI.

Castillo Solórzano, Alonso de (1626). Jornadas alegres. Madrid: Iuan Gonçalez, [BNE: $\mathrm{R}-279]$.

(1909). Jornadas alegres. Emilio Cotarelo y Mori (ed.). Madrid: Librería de los Bibliófilos Españoles, Colección selecta de Antiguas Novelas Españolas, Tomo XI. (2013). Noches de placer. Giulia Giorgi (ed.). Madrid: Sial Ediciones.

Cervantes, Miguel de (2004). Don Quijote de la Mancha, Francisco Rico (ed.). Madrid: Real Academia española, Alfagara.

(2005). Viaje del Parnaso. En Juan Carlos Peinado (ed.), Obras completas. Madrid: Cátedra, pp. 1257-1354.

Cremona, Nicolas (2010). «Les histoires tragiques du début du Xvire siècle: vers un textespectacle». En Charlotte Bouteille-Meister y Kjerstin Aukrust (coord.), Corps sanglants, souffrants et macabres (ХVIe-XVIIe siècle). París: Presses Sorbonne Nouvelle, pp. 189-201.

Didi-Huberman, Georges (1998). «Abrir a Venus». En El desnudo en el Museo del Prado. E. Catalayud (trad.). Madrid: Museo del Prado-Galaxia Gutenberg, pp. 371-390.

Dixon, Víctor (1958). «La mayor confusión. Sobre la cuarta novela de los Sucesos y prodigios de amor». Hispanófila, 3, pp. 17-26.

Dubors, Claude-Gilbert (1973). Le Baroque. Profondeurs de l'apparence. París: Larousse.

DunN, Peter N., (1952). Castillo Solózano and the Decline of Spanish Novel. Oxford: Basil Blackwell.

FrENK, Margit (1977). «El personaje singular: un aspecto del teatro del Siglo de Oro», NRFH, 26, pp. 480-498.

Giorgi, Giulia (2012). «"Novelar muy a imitación de lo de Italia”: Castillo Solórzano, lector de Sansovino». En Rafael Bonilla Cerezo, José Ramón Trujillo y Begoña Rodríguez (coord.). Novela y teatro en el Barroco español. Studia in honorem Prof. Anthony Close. Madrid: Sial Ediciones, pp. 77-85.

Goytisolo, Juan (1977). «El mundo erótico de María de Zayas». En Disidencias. Barcelona: Seix Barral, pp. 63-115.

Historias trágicas exemplares, sacadas del Bandello Veronés (1603). Valladolid: Lorenço de Ayala.

JACQues-Chaquin, Nicole, y Sophie Houdard (coord.) (1998). Curiosité et libido sciendi de la Renaissance aux Lumières. Fontenay-aux-Roses: ENS Éditions, 2 vols.

JEANNET, Michel (2003). Éros rebelle. Littérature et dissidence à l'âge classique. París: Seuil. Jouve, Vincent (1992). L'effet-personage dans le roman. París: PUF. (1992). «Pour une analyse de l'effet-personnage». Littérature, 85, pp. 103-111.

LASPÉRAs, Jean-Michel (1987). La nouvelle au Siècle d'Or. Université de Montpellier: Éditions du Castillet. 
Lope de Vega (1990). El perro del hortelano. El castigo sin venganza. A. David Kossoff (ed.). Madrid: Castalia.

Mattews Grieco, Sarah F. (1991). Ange ou diablesse. La représentation de la femme au хиле Siècle. París: Flammarion.

Moll, Jaime (1974). «Diez años sin licencias para imprimir comedias y novelas en los reinos de Castilla: 1625-1634». Boletín de la Real Academia Española, 54, pp. 97-103.

Pech, Thierry (2000). Conter le crime. Droit et littérature sous la Contre-Réforme: Les histoires tragiques (1559-1644). París: Honoré Champion.

PéRez de Montalbán, Juan (2014). Sucesos y prodigios de amor [en línea], Enrique Suárez Figaredo (ed.). Lemir, 18, pp. 611-800. Consultado el 22. 09. 2014, parnaseo.uv.es/ lemir/Revista/Revista18/Textos/05_Montalban_Prodigios_de_Amor.pdf

PIÑA, Juan de (1627). Varias fortunas. Madrid: Iuan Gonçález.

Quignard, Pascal (2005). El sexo y el espanto. Silvio Mattoni (trad.). Buenos Aires: Ediciones literales.

Real Academia Española (1990). Diccionario de Autoridades. Madrid: Gredos, 3 vols.

Rey HazAs, Antonio (1990). «El erotismo en la novela cortesana». Edad de Oro, 9, pp. 271-288.

Ripoll, Begoña (1991). La novela barroca. Catálogo bio-bibliográfico (1620-1700). Salamanca: Universidad de Salamanca.

Rodríguez CuAdros, Evangelina (1987). Novelas amorosas de diversos ingenios del siglo XVII. Madrid: Castalia.

Sebastián López, Santiago (2001). La mejor emblemática amorosa del barroco: Heinsius, Vaenius y Hoof. Ferrol: Sociedad de Cultura Valle Inclán.

VAenius, Otto (1608). Amorum emblemata [en línea]. Emblem Project Utrecht. Consultado el 21-09-2014, http://emblems.let.uu.nl/v1608frontl.html

ZERARI, María (1995). «Figures de la cruauté dans les Novelas amorosas de José Camerino». En Augustin Redondo (éd.), Les relations entre hommes et femmes en Espagne aux xvie et XVIIe siècles. Publications de la Sorbonne: Presses de la Sorbonne Nouvelles, pp. 175-186.

(2012). «Le «cerveau noir» des nouvellistes. Remarques chromatiques sur la nouvelle post-cervantine ». En Yves Germain y Araceli Guillaume-Alonso (coord.), Les couleurs dans l'Espagne du Siècle d'Or. París: PUPS, pp. 267-285.

(2012). «Novela ou "nonada"? Notes sur la nouvelle au Siècle d'Or». En Paloma Bravo, Cécile Iglesias y Guiseppe Sangirardi (coord.), La Renaissance des genres. Pratiques et théories des genres littéraires en Italie et Espagne (Xve-XVIIe siècles). Dijon: Université de Bourgogne, pp. 267-281. 
Furor in fabula: La CRUEL aragonesa de CAstillo SolóRzano (o De la dama monstruo)

RESUMEN: Historia amorosa por antonomasia, La cruel aragonesa, del prolífico Alonso de Castillo Solórzano, pertenece a ese grupo de novelas cortas del Barroco que, con pretexto deleitoso y moralizador, dibujan un amor desenfrenado teñido de violencia criminal. Pese a las imperfecciones del texto, la novela posee cierto poder de fascinación gracias a lo que la crítica ha llamado el «efecto personaje». De hecho, el valor de la novela radica ante todo en el bosquejo de una dama monstruo: versión áurea de la furiosa trágica.

Palabras clave: Castillo Solórzano, Crueldad, Curiositas, Efecto personaje, Furor, Historias trágicas, La cruel aragonesa, Tragedia.

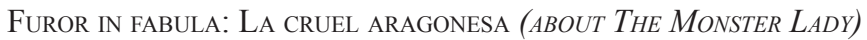

ABSTRACT: Love story par excellence, La cruel aragonesa, written by the prolific novelist Alonso de Castillo Solórzano, belongs to that group of Baroque short novels that, with delightful and supposedly moralistic pretext, draw a wild love dyed of criminal violence. Despite the imperfections of the text, the short novel has a certain power of fascination because of what critics have called the "character-effect». In fact, the value of the novel lies mainly in the design of a monster lady: golden version of the tragic furious woman. Keywords: Castillo Solórzano, Character-effect, Cruelty, Curiositas, Furor, La cruel aragonesa, Tragedy, Tragic stories. 
Evangelina Rodríguez Cuadros (Universitat de València)

Novela cortesana, novela barroca, novela corta: de la incertidumbre al canon .9

Mita Valvassori (Universidad de Los Lagos)

El modelo narrativo del Decamerón en la Edad de Oro: una vieja historia .21

Antonio Gargano (Università degli Studi di Napoli Federico II)

«Difficile est proprie communia dicere»: el género de la novella entre

Boccaccio y Cervantes

Guillermo Carrascón (Università degli Studi di Torino)

Apuntes para un estudio de la presencia de Bandello en la

novela corta del siglo XVII

Leonardo Coppola (Università degli Studi «G. d'Annunzio» di Chieti-Pescara)

La proyección de Straparola en la novela española del Siglo de Oro desde una perspectiva editorial

Mireia Aldomì García

Didactismo, género literario y lector en Giraldi Cinzio.

María Jesús Zamora (Universidad Autónoma de Madrid)

«...En tiempo menos discreto que el de agora, aunque de hombres más sabios, se

Ilamaban a las novelas cuentos». La novela corta y el cuento en el Siglo de Oro.....109

Marcial Rubio (Università degli Studi «G. d'Annunzio» di Chieti-Pescara)

La contribución de Cervantes a la novela barroca: la ejemplaridad. .125

PIERRe Darnis (Université Bordeaux Montaigne)

La fuerza de la sangre, La ilustre fregona $y$ Las dos doncellas: ¿tres tipos

folclóricos?

María Soledad ArRedondo (Universidad Complutense de Madrid)

De La gitanilla $a$ La sabia Flora malsabidilla. El género, el personaje

y el matrimonio

Antonella Gallo (Università degli Studi di Verona)

Fabulaciones en equívocos burlescos: la Chrónica del monstro imaginado (1615)

de Alonso de Ledesma y novela corta barroca

David GonZález Ramírez (Universidad de Málaga)

El filósofo del aldea (1625) de Baltasar Mateo Velázquez: recepción textual

e hipótesis autorial.

Jonathan BRAdBury (University of Exeter)

La narrativa breve en la miscelánea del siglo XVII 
Cristina Castillo Martínez (Universidad de Jaén)

«La fuente del desengaño»: de las Noches de invierno de Eslava a la Tercera

Diana de Tejeda.

María Zerari (Université Paris-Sorbonne, CLEA)

Furor in fabula: La cruel aragonesa de Castillo Solórzano (o de la dama monstruo).. 241

Giulia Giorgi (Università degli Studi di Ferrara)

Alonso de Castillo Solórzano reescritor de sí mismo: algunas notas sobre los

Escarmientos de amor moralizados y el Lisardo enamorado .257

Angela Fabris (Alpen-Adria-Universität Klagenfurt)

El diálogo con el público y los espacios reales y de maravilla en

Casos prodigiosos y cueva encantada de Juan de Piña .267

María Rocío LePe García (IES San Sebastián, Huelva)

La traducción inglesa de Hipólito y Aminta: una adaptación

con fines comerciales 281

Andrea Bresadola (Università degli Studi di Udine)

La novela española en la Italia del siglo XVII: el caso de Il Feniso

de Francisco de Quintana

José Teruel (Universidad Autónoma de Madrid)

El triunfo del Desengaño. Marco y desengaño postrero de la Parte segunda

del Sarao y entretenimiento honesto, de María de Zayas

Nieves Romero-Díaz (Mount Holyoke College)

Lecturas alternativas en la Novela del fin bueno en mal principio

de doña Ana Francisca Abarca de Bolea.

Shifra Armon (University of Florida)

Compromiso y distanciamiento en La Venus de Ferrara

de Mariana de Carvajal Saavedra

Mechthild Albert (Rheinische Friedrich-Wilhelms-Universität Bonn)

Las "noches": un subgénero novelístico en perspectiva comparada.... .365

Fernando Copello Jouanchin (Université du Maine, Le Mans)

El mueble en la novela corta del Siglo de Oro: algunas reflexiones

en torno a la cama

Ilaria Resta (Università del Salento):

De la novella al entremés pasando por la novela corta: reescrituras del cuento

La gara delle tre mogli del Cieco di Ferrara. 


\section{EDAD DE ORO}

Revista de Filología Hispánica XXXIII

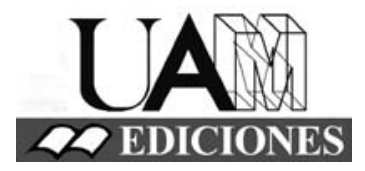




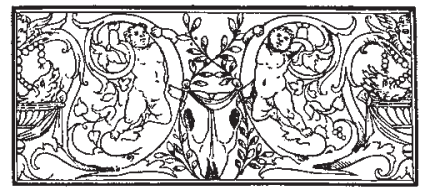

\section{Edad de Oro. Revista de Filología Hispánica}

ISSN: 0212-0429

Dirección:

Teodosio Fernández

Secretaría y edición:

José Ramón Trujillo

Coordinador del volumen XXXIII:

Rafael Bonilla Cerezo

Comité científico internacional:

Carlos Alvar (Univ. de Ginebra)

Ignacio Arellano (Univ. de Navarra)

Javier Blasco (Univ. de Valladolid)

Alberto Blecua (UAB)

Jean Canavaggio (Univ. de París X)

Laura Dolfi (Univ. de Turín)

Aurora Egido (Univ. de Zaragoza)

Víctor García de la Concha (RAE)

Luciano García Lorenzo (CSIC)

Joaquín González Cuenca (Univ. de Castilla-

La Mancha)

Agustín de La Granja (Univ. de Granada)

Begoña López Bueno (Univ. de Sevilla)

Michel Moner (Univ. de Toulouse III)

Joan Oleza (Univ. de Valencia)

Alfonso Rey (Univ. de Santiago)

Lina Rodríguez Cacho (Univ. de Salamanca)

Leonardo Romero Tobar (Univ. de Zaragoza)

Aldo Ruffinatto (Univ. de Turín)

Lía Schwartz (City University of New York)
Redacción y admisión de originales:

Teodosio Fernández

Edad de Oro

Departamento de Filología Española

Universidad Autónoma de Madrid

28049 Madrid (España)

Tfno.: +0034 914974090

correo: teodosio.fernandez@uam.es

Distribución, suscripción y venta:

Servicio de Publicaciones de la UAM

Universidad Autónoma de Madrid

28049 Madrid (España)

Intercambio de publicaciones:

Biblioteca de la Facultad de Filosofía y

Letras (UAM)

Universidad Autónoma de Madrid

28049 Madrid (España)

Han colaborado en este volumen:

Departamento de Filología Española (UAM)

Facultad de Filosofía y Letras (UAM)

Proyecto I+D FFI2013-41264-P La novela

corta del siglo XVII: estudio y edición (y II)

Edad de Oro se recoge en las siguientes bases de datos: SCOPUS, MLA Database, HLAS, Latindex, PIO-Periodical Content Index, ISOC, Dialnet, MIAR, ERIH, DICE, Sumaris CBUC, Ulrich's. Se encuentra evaluada en CIRC: A; INRECH: primer cuartil, posición 6 de 50; MIAR difusión ICDS live: 9.977; SCImago Journal \& Country Rank: H Index 2, SJR 0,101, Q4; RESH índice de impacto: 0.162; ERIH: A INT1; Carhus Plus+: B. 